\title{
Follow-up after curative treatment for breast cancer: why do we still adhere to frequent outpatient clinic visits?
}

Citation for published version (APA):

Kimman, M. L., Voogd, A. C., Dirksen, C. D., Falger, P. R. J., Hupperets, P. S. G. J., Keymeulen, K. B. I. M., Hebly, M. H., Dehing-Oberije, C. J. G., Lambin, P., \& Boersma, L. J. (2007). Follow-up after curative treatment for breast cancer: why do we still adhere to frequent outpatient clinic visits? European Journal of Cancer, 43(4), 647-653. https://doi.org/10.1016/j.ejca.2006.12.002

Document status and date:

Published: 01/01/2007

DOI:

10.1016/j.ejca.2006.12.002

Document Version:

Publisher's PDF, also known as Version of record

\section{Document license:}

Taverne

Please check the document version of this publication:

- A submitted manuscript is the version of the article upon submission and before peer-review. There can be important differences between the submitted version and the official published version of record.

People interested in the research are advised to contact the author for the final version of the publication, or visit the DOI to the publisher's website.

- The final author version and the galley proof are versions of the publication after peer review.

- The final published version features the final layout of the paper including the volume, issue and page numbers.

Link to publication

\footnotetext{
General rights rights.

- You may freely distribute the URL identifying the publication in the public portal. please follow below link for the End User Agreement:

www.umlib.nl/taverne-license

Take down policy

If you believe that this document breaches copyright please contact us at:

repository@maastrichtuniversity.nl

providing details and we will investigate your claim.
}

Copyright and moral rights for the publications made accessible in the public portal are retained by the authors and/or other copyright owners and it is a condition of accessing publications that users recognise and abide by the legal requirements associated with these

- Users may download and print one copy of any publication from the public portal for the purpose of private study or research.

- You may not further distribute the material or use it for any profit-making activity or commercial gain

If the publication is distributed under the terms of Article 25fa of the Dutch Copyright Act, indicated by the "Taverne" license above, 


\title{
Current Perspective
}

\section{Follow-up after curative treatment for breast cancer: Why do we still adhere to frequent outpatient clinic visits?}

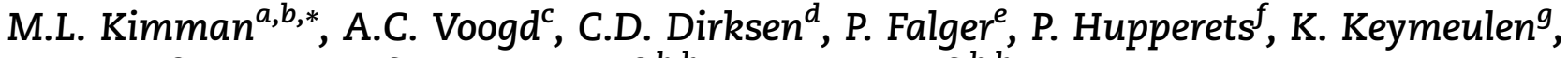 \\ M. Hebly ${ }^{g}$, C. Dehing ${ }^{a}$, Ph. Lambin ${ }^{a, b, h}$, L.J. Boersma ${ }^{a, b, h}$ \\ ${ }^{a}$ MAASTRO Clinic, Maastricht, The Netherlands \\ bepartment GROW - MAASTRO, Maastricht University, The Netherlands \\ ${ }^{\mathrm{C}}$ Department of Epidemiology, Maastricht University, The Netherlands \\ ${ }^{\mathrm{d}}$ Department of Clinical Epidemiology and Medical Technology Assessment, University Hospital Maastricht, The Netherlands \\ e Department of Medical Psychology, University Hospital Maastricht, The Netherlands \\ ${ }^{f}$ Department of Medical Oncology, University Hospital Maastricht, The Netherlands \\ gDepartment of Surgery, University Hospital Maastricht, The Netherlands \\ ${ }^{\mathrm{h}}$ Department of Radiation Oncology (MAASTRO), University Hospital Maastricht, The Netherlands
}

\section{A R T I C L E I N F O}

Article history:

Received 4 August 2006

Received in revised form

10 November 2006

Accepted 4 December 2006

Available online 23 January 2007

\section{Keywords:}

Breast neoplasms

Follow-up

Psychosocial support

Quality of life

Recurrence

Effectiveness

Economic evaluation

\begin{abstract}
A B S T R A C T
Follow-up after curative treatment for breast cancer consists of frequent outpatient clinic visits, scheduled at regular intervals. Its aim is primarily to detect local disease recurrence, or a second primary breast cancer, but also to provide information and psychosocial support. The cost-effectiveness of these frequent visits is being questioned however, leading to a search for less intensive follow-up strategies, such as follow-up by the general practitioner, patient-initiated or nurse-led follow-up or contact by telephone. These strategies are generally considered to be safe, but they are not yet widely accepted in clinical practice. Since brief interventions based on self-education and information have been shown to be able to improve quality of life, we hypothesise that these interventions may lead to a better acceptance of reduced follow-up by both patients and professionals.
\end{abstract}

(c) 2006 Elsevier Ltd. All rights reserved.

\section{Introduction}

After curative treatment for breast cancer, women frequently attend scheduled follow-up examinations. The main objective of these examinations is to detect local disease recur- rence or a second primary breast cancer in an early stage, hoping that this may increase the chances of cure. Yet, follow-up should also provide information and psychological support. Another aim is to collect data on late effects of surgery, radiotherapy and chemotherapy for audit or research

\footnotetext{
* Corresponding author: Address: MAASTRO Clinic, P.O. Box 5800, 6202 AZ Maastricht, The Netherlands. Tel.: +31 884455666 ; fax: +31 88 4455667.

E-mail address: merel.kimman@maastro.nl (M.L. Kimman).

0959-8049/\$ - see front matter (c) 2006 Elsevier Ltd. All rights reserved.

doi:10.1016/j.ejca.2006.12.002
} 
and to provide feedback to physicians. ${ }^{1,2}$ However, there has been much debate whether these objectives of breast cancer follow-up are adequately met in current clinical practice. ${ }^{3,4}$ First, neither the frequency ${ }^{5,6}$ nor the intensity ${ }^{7,8}$ of followup has been shown to influence the chances of cure. Second, there is a general feeling amongst clinicians that there is limited time during the outpatient clinic visit to adequately address often complex psychosocial issues. Indeed, patients often feel uncomfortable with expressing emotional concerns and asking questions. ${ }^{9}$ Also, it has been demonstrated that the outpatient clinic visits may induce anxiety because of the risk of detecting tumour relapse. ${ }^{10}$ Finally, to provide feedback to the professionals on the effectiveness and side-effects of their treatments, less frequent follow-up may be sufficient as well. Not only do the current frequent follow-up strategies seem to miss their most important goals, but they also depend heavily on expensive and scarce specialised knowledge for routine history taking and physical examinations. Financial constraints force oncologists and policy makers to search for alternative, more cost-effective, follow-up strategies. The aim of this paper is to explore the literature for scientific evidence why physicians and patients should still adhere to frequent outpatient clinic visits after breast cancer treatment, as recommended in the current European and American guidelines for breast cancer follow-up. In addition, we summarise the studies on alternative strategies, focussing on the two main goals of breast cancer follow-up: (1) detecting recurrences or new primaries; and (2) providing psychosocial support to improve quality of life (QoL). Finally, implications for future research are discussed, taking into account the existing knowledge on patients' needs and expectations.

\section{Current follow-up strategies and their effectiveness}

In Europe, the European Society for Medical Oncology (ESMO) recommends that follow-up of primary breast cancer consists of history taking and physical examinations every 3-6 months in the first 3 years after treatment, every 6-12 months for the next 3 years, and annually thereafter. A mammography is taken every 1-2 years. More intensive surveillance (i.e. with additional radiological examinations of liver, lungs and bones and laboratory tests) is not routinely recommended for asymptomatic patients. ${ }^{11}$ In a recent update of the follow-up guidelines by the American Society of Clinical Oncology (ASCO), a similar frequency of history taking, physical examination and mammography was proposed. However, there is no high-level evidence supporting these frequent follow-up visits and the current practice of mammography surveillance. ${ }^{12}$

\subsection{Effectiveness of follow-up on detecting recurrent disease}

Intensive surveillance used to be common practice in the seventies and eighties. Large randomised trials by Roselli del Turco and colleagues ${ }^{8}$ and the GIVIO investigators ${ }^{7}$ have shown that follow-up based on routine outpatient clinic visits combined with an annual mammography is as effective with regard to overall survival, as follow-up with intensive surveillance. Since then, several papers with varying levels of evidence, have been published questioning even the effectiveness of routine outpatient clinic visits. ${ }^{6,13-15}$ Wheeler and colleagues performed a longitudinal study of 416 consecutive patients after the diagnosis of primary breast cancer and found that the frequent early follow-up provided no clear clinical gain for the great majority of patients, since early relapse was rare in the first year. ${ }^{13}$ Te Boekhorst and colleagues conducted a retrospective review in 270 patients with recurrent breast cancer and also found the clinical impact of the follow-up to be low, as most patients had symptomatic recurrences (63\%). When specifically looking at loco regional recurrences, routine follow-up was more effective, detecting $66 \%$ of these recurrences. However, early detection did not translate into improved survival. ${ }^{14}$

Stronger evidence is available from a meta-analysis of 12 studies by de Bock and colleagues. This analysis included 5045 breast cancer patients and 378 isolated loco regional recurrences and showed that approximately $40 \%$ of recurrences were diagnosed in asymptomatic patients during routine visits or routine tests $(95 \%$ confidence interval $35 \%$ to $45 \%)$. Forty-one percent of recurrences were diagnosed outside these routine visits and tests and $18 \%$ of recurrences were diagnosed in symptomatic patients at their routine visits. Although the rate of women diagnosed during routine follow-up with an asymptomatic recurrence seems significant, the overall incidence of loco regional recurrence is low. Thus by using frequent routine follow-up in the first two years, much effort is needed to detect only a very small proportion of curable loco regional recurrences early. ${ }^{15}$

A simulation study by Jacobs and colleagues confirmed these findings. They tested various follow-up strategies with regard to the frequency of outpatient clinic visits. It was found that the gain in life expectancy with standard followup compared to no follow-up examination at all is only about 2 months in breast cancer patients aged 50 years and treated with curative intent. In older women, the gain was even less. ${ }^{6}$

\subsection{Effectiveness of follow-up in providing psychosocial support}

Providing psychosocial support to improve QoL is another important aim of the follow-up. Breast cancer has an enormous psychological impact on patients and their partners, triggering fears of prolonged suffering, disability and a foreshortened life perspective. High levels of anxiety, depression, and distress are estimated to occur in about $35 \%$ of patients after treatment. ${ }^{16}$ These patients should be identified and referred for specialised psychosocial support. Others depend on the follow-up visits to the medical specialist for information and some form of psychosocial support. The question remains whether short routine outpatient clinic visits are sufficient and appropriate enough for this type of support. Several studies have indicated that they are not.,? Pennery and colleagues conducted a cross-sectional survey among 24 breast cancer patients of different age and found that most patients felt hurried and uncomfortable with expressing emotional concerns or asking questions during the outpatient clinic visit. Eighteen women stated that they would prefer to receive all or part of their follow-up from a breast care nurse. ${ }^{9}$ Allen interviewed six breast cancer patients and found that the 
scheduled clinic visits produced anxiety about breast cancer recurrence in women who were otherwise free from this particular form of anxiety. Thus, anxiety created the need to attend the clinic in order to gain reassurance about wellbeing. ${ }^{10}$ Since the numbers of patients in these studies were rather small, more research investigating the quality of psychosocial support during follow-up is urgently needed.

\section{What do patients need and expect?}

Several studies investigated breast cancer patients' needs after treatment and their expectations about the follow-up examinations, by using interviews or questionnaires. Important needs that patients expressed were reassurance and social support, ${ }^{9}$ confirmation, continuity, accessibility and information, ${ }^{17}$ cancer expertise of clinical staff and a good relationship with the doctor. ${ }^{18}$ Renton and colleagues surveyed the opinion of 134 women attending a breast cancer follow-up clinic to establish what they considered the most important topics for discussion at the follow-up. Information on risk of recurrence (70\%), benefits and side-effects of treatment (61\%) and the risk of breast cancer affecting their daughters (41\%) were highlighted the most. ${ }^{19}$ A cross-sectional survey by de Bock and colleagues showed that patients' expectations of routine follow-up were high and sometimes unrealistic. Seventy-four out of $84 \mathrm{pa}-$ tients $(88 \%)$ believed that the early detection of distant metastases would contribute to a cure. Therefore, most of these patients preferred additional investigations to be a part of the follow-up and more than half preferred lifetime follow-up, performed by a medical specialist. ${ }^{20}$

These studies show that women differ greatly in their needs and preferences regarding follow-up. Moreover, the needs and preferences deviate from available evidence on the effectiveness of routine follow-up, stressing the need for more information and education about the particular aims and effects of follow-up.

\section{Alternative follow-up strategies for breast cancer to reduce clinical workload and costs}

To make more efficient use of scarce specialised expertise, reduced follow-up strategies have been proposed. These include follow-up by the general practitioner or nurse, and patient-initiated follow-up (see Table 1a). Also, replacing clinic visits by telephone interviews is increasingly being used as a presumably safe and cost-effective way of follow-up.

\subsection{Follow-up by the general practitioner}

In a randomised study by Grunfeld and colleagues, 296 women with stage $\leqslant$ III breast cancer received routine followup either in the hospital or in general practice. Results indicated that the general practice follow-up was not associated with an increase in time to diagnosis of recurrence, increase in anxiety, or deterioration in health related QoL and patients' satisfaction with the follow-up was higher, compared to the hospital follow-up. ${ }^{21,22}$ The economic evaluation showed that the mean costs per patient for 18 months of follow-up in general practice were only one-third of those per patient in the hospital follow-up. ${ }^{23}$ A later similarly randomised trial by
Grunfeld and colleagues with long-term follow-up in 986 patients showed that the follow-up can be offered by the general practitioner without concern that important recurrence-related serious events will occur more frequently or that health-related QoL will be affected negatively compared to the routine follow-up. ${ }^{24}$

\subsection{Patient-initiated follow-up}

In a study by Gulliford and colleagues, the experiences of breast cancer patients who attended an outpatient clinic for the follow-up were compared with those in whom the routine follow-up was restricted to a single visit only after mammography. All patients were advised to examine their breasts each month and to request an appointment if they felt a lump or developed any other symptom. Of 211 eligible patients, 196 (93\%) opted for randomisation in the study. No increased use of local practitioner services or telephone calls to the hospital was apparent in the group randomised to less frequent follow-up. Although QoL was not analysed in this study, this cohort of patients was highly supportive of the option to pursue less frequent follow-up. ${ }^{25}$ Brown and colleagues compared routine outpatient clinic follow-up and patientinitiated follow-up in women treated for stage I breast cancer in a small randomised trial $(n=62)$, and found that the patient-initiated follow-up was a safe and possibly cost-effective alternative to the routine follow-up for women at a low risk of recurrence. ${ }^{26}$ However, this study was not sufficiently powered to draw firm conclusions.

\subsection{Nurse-led telephone follow-up}

A literature review by Cox and Wilson on nurse-led services and telephone interventions in follow-up for patients with all forms of cancer showed that nurse-led follow-up services were acceptable, appropriate and effective. ${ }^{27}$ Specifically looking at breast cancer, Koinberg and colleagues conducted a randomised trial comparing usual follow-up by the medical specialist $(n=131)$ with nurse-led follow-up on demand $(n=133)$. In the nurse-led group, patients met with an experienced nurse three months after surgery. They received information about how to recognise recurrence and were requested to contact the nurse for any concerns related to breast cancer. The nurse arranged a mammography at oneyear intervals and reported the results by telephone or letter. No statistically significant differences were found in the levels of anxiety, depression or satisfaction with the follow-up between the two groups. In addition, there were no differences in time to recurrence or death. These data suggest equal validity of both approaches, but the limited number of patients prohibits drawing firm conclusions on this subject. Furthermore, the nurse-led group reported 450 less visits to the medical specialist but 177 more phone calls and 88 more visits to the nurse, than the specialist-led group. ${ }^{28}$ No costs were calculated, but it may be thought that the substantial reduction in medical specialist visits would have led to cost reduction. Similar results were found in trials investigating the nurse-led telephone follow-up as an alternative to the conventional outpatient clinic follow-up in other cancers. ${ }^{29,30}$ 
Table 1a - Trials investigating strategies for breast cancer follow-up aimed at reducing clinical workload and costs

Author (year) Aim/goal of the study Design/participants

$\begin{array}{lll}\text { Grunfeld et al. }(1996,1999) & \begin{array}{l}\text { To assess the effect of transferring the follow-up from hospital } \\ \text { to general practice (GP) }\end{array} & \begin{array}{l}\text { RCT: } 296 \text { women with stages I, } \\ \text { II or III breast cancer }\end{array}\end{array}$

Grunfeld et al. (2006)

To assess whether GP follow-up is a safe and acceptable alternative to specialist follow-up

Gulliford et al. (1997)

To compare regular follow-up with follow-up restricted to the time of mammography

Brown et al. (2002)

Koinberg et al. (2004)
RCT: 968 women with stages I, II or III breast cancer

RCT: 211 women with stages I, II or III breast cancer

RCT: 61 women with stage I breast cancer

RCT: 264 women with stages and II breast cancer
To assess the benefits of clinic follow-up compared to patient initiated follow-up

To compare the follow-up by the physician with the nurse-led follow-up on demand

\section{Results}

GP follow-up was not associated with an increase in time to diagnosis of recurrence or decreased quality of life (QoL). No significant differences between groups in anxiety or depression scores were found. The GP group indicated greater satisfaction than the hospital group.

No differences in recurrences, recurrence-related serious clinical events or health related QoL were found between the GP group and the specialist group.

The patients undergoing less frequent follow-up did not increase their use of GP or telephone services. The patients were highly supportive to pursue less frequent follow-up.

No differences in QoL, psychological morbidity or satisfaction with care were found between the groups. No statistically significant differences in the levels of anxiety, depression and satisfaction were found between the groups. Also, no differences concerning time to recurrence or death were detected.
Antoni et al. (2001)

Koinberg et al. (2006)
To test the effects of a group cognitive- behavioral stress management intervention

To compare a multidisciplinary educational programme (MP) with traditional follow-up visits to a physician
RCT: 100 women with stages 0 , I, II or III breast cancer

Prospective non-randomised study: 96 women with stages I or II breast cance

\section{Results}

The educational intervention improved self-esteem and body image and reduced disturbing thoughts. Peer-assisted discussion groups were only helpful for women who lacked support from their partners, but harmful for women with high support levels.

The intervention reduced prevalence of moderate depression, but did not affect other measures of emotional distress.

Women in the MP increased their physical and functional wellbeing. Women with traditional follow-up increased functional well-being, while social/family well being decreased over time. Women with the traditional follow-up also scored lower in their overall coping capacity. 


\section{Interventions after cancer treatment to provide psychosocial support}

A number of studies have been performed using various group intervention formats to provide psychosocial support for cancer patients. Results varied and refusal rates for extensive programmes were often high. ${ }^{16}$ Only few studies focussed on women treated for breast cancer (see Table 1b). Helgeson and colleagues found in a randomised trial $(n=312)$ that an education-based intervention increased psychological and physical functioning by enhancing self-esteem and reducing disturbing intrusive thoughts about the illness, both immediately following and 6 months after the intervention. ${ }^{31}$ In addition, peer-assisted discussion groups were helpful for a subgroup of women who lacked emotional support from their partners, but could be harmful for women with high support levels. ${ }^{32}$ The positive effects of the education intervention dissipated with time, but the differences with the control group remained significant over a 3-year period $(n=252) .{ }^{33}$ A randomised trial by Antoni and colleagues $(n=100)$ tested effects of a 10-week group cognitive-behavioural stress management intervention that focussed on coping with daily stressors related to breast cancer and on optimising one's use of social resources. The intervention reduced prevalence of moderate depression and enhanced optimism about the future, but did not affect other measures of emotional distress, such as mood disturbance and thought intrusion and avoidance. ${ }^{34} \mathrm{~A}$ recently published non-randomised study by Koinberg and colleagues compared a short multidisciplinary educational programme $(n=50)$ with the traditional follow-up visits to a physician $(n=46)$ after breast cancer surgery. The programme was led by a specialised nurse in oncology and comprised four sessions of lectures and discussions on topics related to breast cancer. The programme aimed to strengthen the self-care ability of the participants, in addition to promoting health and to facilitating a sense of coherence. Results of this study indicated that the educational programme was comparable to a traditional physician follow-up programme in terms of wellbeing, aspects of self-care and coping ability, and could thus be an alternative to the traditional physician follow-up. ${ }^{35}$

\section{Implications for future research}

In summary, the randomised clinical trials investigating the effects of less frequent follow-up $\mathrm{p}^{25,26}$ and nurse-led follow$\mathrm{up}^{28}$ were too small to allow firm conclusions on the safety of these reduced follow-up strategies. Nevertheless, several retrospective studies ${ }^{14,15}$ and the simulation study of Jacobs and colleagues ${ }^{6}$ strongly suggest that only few patients would benefit from the frequent routine follow-up visits in terms of the early detection of curable loco regional recurrence. Since this early detection of loco regional recurrences does also not seem to translate into improved survival, ${ }^{13}$ the cost-effectiveness of frequent follow-up in terms of survival benefit is highly questionable. In addition to primarily clinical considerations, routine follow-up also has a psychosocial component, but there is only limited time during outpatient clinic visits to address this. Moreover, it has been suggested that these visits may induce a high level of anxiety. ${ }^{10}$
In the last decade, alternative strategies for the follow-up have been proposed. Trials investigating less frequent follow-up, nurse-led follow-up and shared care with the patient's family doctor, show promising results with respect to QoL and patient satisfaction. ${ }^{24,25,28}$ Additionally, a short educational group programme may be able to reduce outpatient clinic visits to the specialist. ${ }^{35}$

Yet, alternative follow-up strategies are not widely applied in clinical practice and the frequent conventional oncologist follow-up is still common practice. Several reasons could explain this situation. First, financial incentives for medical specialists might play a role. A more likely explanation could be the, probably false, perception of many medical specialists that patients need frequent reassurance. In addition, many patients have false expectations that frequent the follow-up visits will result in a better overall survival. ${ }^{20}$ Finally, another reason may be that trial-based economic evaluations, supporting the conclusions that reduced strategies are indeed cost-effective to society, are scarce.

We hypothesise that improvements in psychosocial support and education of patients may lead to better acceptance rates in both patients and medical specialists with respect to a reduced follow-up strategy. Furthermore, we recognise that the cost-effectiveness of both reduced follow-up policies and educational group programmes should be determined to justify the implementation of new strategies.

In the Netherlands, we have started a randomised trial investigating the cost-effectiveness of four different followup strategies for primary breast cancer patients. These strategies include the routine frequent outpatient clinic visits as described in the current guidelines; follow-up in the first two years reduced to annual mammography, with telephone interviews by a nurse practitioner at the other time points of the routine strategy (3, 6, 9 and 18 months) and; each of these strategies combined with a short educational group programme, focussing on enhancing the QoL. ${ }^{36}$ In this study, nurse practitioners have a major role in the follow-up. The increased use of nurse practitioners is an important trend in cancer care; they are uniquely educated to provide quality specialty care, are easily accessible and they can provide continuity of care to the patients. Thus, their role may lead to high patients' satisfaction. Also, they are likely to reduce costs associated with the follow-up.

\section{Conclusion}

The value of the frequent outpatient follow-up in the first few years after curative treatment for breast cancer is still a controversial issue. There is no strong evidence that routine outpatient clinic visits are effective with regard to the detection of recurrences, as most recurrences are detected between scheduled appointments. Moreover, routine follow-up has a major impact on costs and staff resources. Therefore, alternative follow-up strategies have been tested and well received by patients, not adversely affecting patient satisfaction or QoL. However, there still seem to be barriers preventing the full fledged implementation of these new strategies in clinical practice. More psychosocial support and better education and information to the patient may lead to a better acceptance of 
reduced follow-up policies. A trial investigating the costeffectiveness of a reduced follow-up strategy, combined with additional psychosocial support and education, is currently underway.

\section{Conflict of interest statement}

None declared.

\section{Acknowledgement}

This research is funded by the Netherlands Organisation for Health Research and Development (Grant No. 945-04-512, ISRCTN 74071417).

\section{R E F E R E N C E S}

1. Rojas MP, Telaro E, Russo A, Coe, L, Fossati, R, et al. Follow-up strategies for women treated for early breast cancer. Cochrane Database Syst Rev 2005(1):CD001768.

2. Rutgers EJ, van Slooten EA, Kluck HM. Follow-up after treatment of primary breast cancer. Br J Surg 1989;76(2):187-90.

3. Brada M. Is there a need to follow-up cancer patients? Eur J Cancer 1995;31A(5):655-7.

4. Dewar J. Follow up in breast cancer. BMJ 1995;310(6981):685-6.

5. Schapira DV. Breast cancer surveillance - a cost-effective strategy. Breast Cancer Res Treat 1993;25(2):107-11.

6. Jacobs HJ, van Dijck JA, de Kleijn EM, Kiemeney LA, Verbeek AL. Routine follow-up examinations in breast cancer patients have minimal impact on life expectancy: a simulation study. Ann Oncol 2001;12(8):1107-13.

7. GIVIO. Impact of follow-up testing on survival and healthrelated quality of life in breast cancer patients. A multicenter randomized controlled trial. The GIVIO Investigators. JAMA 1994;271(20):1587-92.

8. Del Turco M Rosselli, Palli D, Cariddi A, Ciatto S, Pacini P, Distante V. Intensive diagnostic follow-up after treatment of primary breast cancer. A randomized trial. National Research Council Project on Breast Cancer follow-up. JAMA 1994;271(20):1593-7.

9. Pennery E, Mallet J. A preliminary study of patients' perceptions of routine follow-up after treatment for breast cancer. Eur J Oncol Nurs 2000;4(3):138-45 [discussion 146-7].

10. Allen A. The meaning of the breast cancer follow-up experience for the women who attend. Eur J Oncol Nurs 2002;6(3):155-61.

11. ESMO. Minimum clinical recommendations for diagnosis, adjuvant treatment and follow-up of primary breast cancer. Ann Oncol 2001;12(8):1047-8.

12. Khatcheressian JL, Wolff AC, Smith TJ, et al. American Society of Clinical Oncology 2006. Update of the breast cancer follow-up and management guidelines in the adjuvant setting. J Clin Oncol 2006;24(31):5091-7.

13. Wheeler T, Stenning S, Negus S, Picken S, Metcalfe S. Evidence to support a change in follow-up policy for patients with breast cancer: time to first relapse and hazard rate analysis. Clin Oncol (R Coll Radiol) 1999;11(3):169-73.

14. te Boekhorst DS, Peer NG, van der Sluis RF, Wobbes T, Ruers TJ. Periodic follow-up after breast cancer and the effect on survival. Eur J Surg 2001;167(7):490-6.
15. de Bock GH, Bonnema J, van der Hage J, Kievit J, van de Velde CJ. Effectiveness of routine visits and routine tests in detecting isolated locoregional recurrences after treatment for early-stage invasive breast cancer: a meta-analysis and systematic review. J Clin Oncol 2004;22(19):4010-8.

16. Clark MM, Bostwick JM, Rummans TA. Group and individual treatment strategies for distress in cancer patients. Mayo Clin Proc 2003;78(12):1538-43.

17. Koinberg I, Holmberg L, Fridlund B. Satisfaction with routine follow-up visits to the physician - the needs of patients with breast cancer. Acta Oncol 2001;40(4):454-9.

18. Adewuyi-Dalton R, Ziebland S, Grunfeld E, Hall A. Patients' views of routine hospital follow-up: a qualitative study of women with breast cancer in remission. Psychooncology 1998;7(5):436-9.

19. Renton JP, Twelves CJ, Yuille FA. Follow-up in women with breast cancer: the patients' perspective. Breast 2002;11(3):257-61.

20. de Bock GH, Bonnema J, Zwaan RE, van de Velde CJ, Kievit J, Stiggelbout AM. Patient's needs and preferences in routine follow-up after treatment for breast cancer. $\mathrm{Br} \mathrm{J}$ Cancer 2004;90(6):1144-50.

21. Grunfeld E, Fitzpatrick R, Mant D, et al. Comparison of breast cancer patient satisfaction with follow-up in primary care versus specialist care: results from a randomized controlled trial. Br J Gen Pract 1999;49(446):705-10.

22. Grunfeld E, Mant D, Yudkin P, et al. Routine follow up of breast cancer in primary care: randomised trial. BMJ 1996;313(7058):665-9.

23. Grunfeld E, Gray A, Mant D, et al. Follow-up of breast cancer in primary care vs specialist care: results of an economic evaluation. Br J Cancer 1999;79(7-8):1227-33.

24. Grunfeld E, Levine MN, Julian JA, et al. Randomized trial of long-term follow-up for early-stage breast cancer: a comparison of family physician versus specialist care. J Clin Oncol 2006;24(6):848-55.

25. Gulliford T, Opomu M, Wilson E, Hanham I, Epstein R. Popularity of less frequent follow up for breast cancer in randomised study: initial findings from the hotline study. BMJ 1997;314(7075):174-7.

26. Brown L, Payne S, Royle G. Patient initiated follow up of breast cancer. Psychooncology 2002;11(4):346-55.

27. Cox K, Wilson E. Follow-up for people with cancer: nurse-led services and telephone interventions. J Adv Nurs 2003;43(1):51-61.

28. Koinberg IL, Fridlund B, Engholm GB, Holmberg L. Nurse-led follow-up on demand or by a physician after breast cancer surgery: a randomised study. Eur J Oncol Nurs 2004;8(2):109-17. discussion 118-20.

29. Helgesen F, Andersson SO, Gustafsson O, et al. Follow-up of prostate cancer patients by on-demand contacts with a specialist nurse: a randomized study. Scand J Urol Nephrol 2000;34(1):55-61.

30. Sardell S, Sharpe G, Ashley S, Guerrero D, Brada M. Evaluation of a nurse-led telephone clinic in the follow-up of patients with malignant glioma. Clin Oncol (R Coll Radiol) 2000;12(1):36-41.

31. Helgeson VS, Cohen S, Schulz R, Yasko J. Education and peer discussion group interventions and adjustment to breast cancer. Arch Gen Psychiatry 1999;56(4):340-7.

32. Helgeson VS, Cohen S, Schulz R, Yasko J. Group support interventions for women with breast cancer: who benefits from what? Health Psychol 2000;19(2):107-14.

33. Helgeson VS, Cohen S, Schulz R, Yasko J. Long-term effects of educational and peer discussion group interventions on adjustment to breast cancer. Health Psychol 2001;20(5):387-92. 
34. Antoni MH, Lehman JM, Kilbourn KM, et al. Cognitivebehavioral stress management intervention decreases the prevalence of depression and enhances benefit finding among women under treatment for early-stage breast cancer. Health Psychol 2001;20(1):20-32.

35. Koinberg I, Langius Eklof A, Holmberg L, Fridlund B. The usefulness of a multidisciplinary educational programme after breast cancer surgery: a prospective and comparative study. Eur J Oncol Nurs 2006;10(4):273-82.

36. Kimman ML, Voogd AC, Dirksen CD, et al. Improving the quality and efficiency of follow-up after curative treatment for breast cancer - rationale and study design of the MaCare trial. BMC Cancer 2007;7(1) [in press]. 